\title{
Complications of Sub-microscopic Plasmodium vivax Malaria among Orang Asli in Pos Lenjang, Kuala Lipis
}

\author{
Mat Salleh, N.H. ${ }^{1}$, Abdul Rahman, M.F. ${ }^{1}$, Samsusah, S. ${ }^{1}$, De Silva, J.R. ${ }^{2}$, Tan, J.H. ${ }^{2}$, Amir, A. ${ }^{2}$, Lau, Y.L. ${ }^{2 *}$ \\ ${ }^{1}$ Lipis District Health Office, 27200 Kuala Lipis, Pahang, Malaysia \\ 2Department of Parasitology, Faculty of Medicine, University of Malaya, 50603 Kuala Lumpur, Malaysia \\ *Corresponding author: lauyeeling@um.edu.my
}

\section{ARTICLE HISTORY}

Received: 10 July 2020

Revised: 25 November 2020

Accepted: 27 November 2020

Published: 25 March 2021

\begin{abstract}
In recent years, increasing cases of Plasmodium vivax complications had been reported all over the world. This former benign Plasmodium species is now recognized to be one of the human malaria parasites that can produce severe disease. In this article, we report two cases of sub-microscopic $P$. vivax malaria confirmed by PCR. Both patients were asymptomatic before treatment. They showed unusual presentations few days after initiation of antimalarial treatment. Both patients had subsequently completed antimalarial treatment and recovered completely.
\end{abstract}

Keywords: Plasmodium vivax; sub-microscopic; acute kidney injury; pulmonary complication.

\section{INTRODUCTION}

Approximately 2.5 billion people are at risk of malaria infection caused by Plasmodium falciparum and Plasmodium vivax (Howes et al., 2016). Among the human malaria species, $P$. vivax is known to be the most widely distributed human malaria. According to Management Guidelines of Malaria in Malaysia, severe malaria usually presents with one or more of the following: cerebral malaria, metabolic acidosis, severe anaemia, hypoglycaemia, acute renal failure or acute pulmonary oedema (Ministry of Health Malaysia, 2014). Severe vivax malaria is defined as for falciparum malaria but with no parasite density thresholds (World Health Organization, 2019). Submicroscopic malaria are malaria with low-density blood-stage malaria infections that are not detected by conventional microscopy (World Health Organization, 2016). Although P. vivax is less pathogenic than $P$. falciparum, it has been associated with complications such as acute respiratory distress syndrome (ARDS), jaundice, severe anaemia and acute renal failure (Prakash et al., 2003; Sarkar et al., 2010).

In 2019, there was a P. vivax outbreak among Orang Asli in Pos Lenjang. Mass blood survey was carried out using blood film for malaria parasite (BFMP) and Polymerase Chain Reaction (PCR) in 3 villages (Unpublished data). A total of 60 sub-microscopic $P$. vivax malaria cases were reported, in which all of them were asymptomatic during the mass screening. Thirty-five of the adult cases of sub-microscopic malaria were started with radical malaria regime treatment in a local transit clinic instead of being admitted to the hospital. The remaining high risk submicroscopic patients (under 5 years old, pregnant, or elderly) were treated in the hospital. Here, we report 2 cases of sub-microscopic P. vivax malaria developing complications post treatment in the local transit clinic.

\section{CASE 1}

A 17-year-old Orang Asli girl who had no symptom of malaria was found to be infected with $P$. vivax in a mass blood survey. BFMP was negative and the infection was confirmed by PCR. She was admitted to a local transit clinic for administration of antimalarial. Baseline blood investigation which include full blood count, renal function test, liver function test and glucose 6 phosphate dehydrogenase (G6PD) was done and the results were normal. The patient was started on artemether-lumefantrine ( 4 tablets of Riamet ${ }^{\circledR}$, twice daily for 3 days) and primaquine ( $30 \mathrm{mg}$ daily for 14 days) as antimalarial treatment. The patient presented with giddiness and vomiting on day- 8 of starting antimalarial treatment. On day- 8 , she was afebrile with blood pressure of $114 / 67 \mathrm{mmHg}$, pulse rate $102 / \mathrm{min}$, respiratory rate $22 / \mathrm{min}$ and oxygen saturation of $95-97 \%$ under room air. Other physical findings were unremarkable. Her haemoglobin reduced from 13.3 $\mathrm{g} / \mathrm{dL}$ to $8.1 \mathrm{~g} / \mathrm{dL}$. Her renal function deteriorated with serum urea increased from $1.8 \mathrm{mmol} / \mathrm{L}$ to $32.7 \mathrm{mmol} / \mathrm{L}$ and serum creatinine from $50 \mu \mathrm{mol} / \mathrm{L}$ to $625 \mu \mathrm{mol} / \mathrm{L}$. Her liver function also showed deranged aspartate transaminase from 17.6 $\mathrm{U} / \mathrm{L}$ to $61.1 \mathrm{U} / \mathrm{L}$. She was referred to a nearby district hospital and was admitted to the intensive care unit. Blood culture and a repeat BFMP were negative. The full blood picture showed evidence of hemolysis with lightly elevated reticulocyte count. She underwent kidney, ureter and bladder ultrasonography but there was no evidence of obstructive uropathy. In view of her worsening renal function and 
oliguria, she was dialyzed 4 times and transfused with 2 pints of packed red blood cells. She was discharged after 19 days with improved renal and liver function. Upon discharge, she continued primaquine $(0.75 \mathrm{mg} / \mathrm{kg})$ once weekly for 8 weeks to complete the course of her treatment. No PCR was repeated prior to or after discharge.

\section{CASE 2}

A 37-year-old Orang Asli lady was found to be infected with $P$. vivax in a Mass Blood Survey. She had no known previous medical illness. BFMP was negative and the infection was confirmed by PCR. She was admitted to a local transit clinic for administration of antimalarial. Baseline blood investigation was carried out for full blood count, renal function test, liver function test and G6PD and it was found to be normal. The antimalarial treatment given was artemether-lumefantrine ( 4 tablets of Riamet ${ }^{\circledR}$, twice daily for 3 days) and primaquine ( $30 \mathrm{mg}$ daily for 14 days). She complained of non-productive cough for 2 days on day- 4 of antimalarial treatment. There was no fever, shortness of breath or chest pain. Her blood pressure was $118 / 63 \mathrm{mmHg}$, pulse rate $140 / \mathrm{min}$, respiratory rate $22 / \mathrm{min}$, and oxygen saturation of $89 \%$ under room air. There was bilateral crepitation in her lungs. Total white count was elevated from $11.1 \times 10^{9} / \mathrm{L}$ to $16.7 \times 10^{9} / \mathrm{L}$. Her chest $\mathrm{X}$-ray $(\mathrm{CXR})$ showed consolidation at the left lower zone. She was then admitted to the hospital for superimposed bacterial lung pneumonia and was given intravenous augmentin and oral azithromycin. During her stay in the ward, she was supported with oxygenation to maintain her saturation to be more than $95 \%$. She did not have any fever throughout her admission. Blood culture and repeated BFMP were negative. After 8 days of admission, she was discharged based on negative BFMP with primaquine treatment to be completed at home.

\section{DISCUSSION}

During the mass screening, PCR method used was nested PCR targeting the $18 \mathrm{~S}$ ribosomal RNA genes (18S rRNA) which had been reported to have $91.9 \%$ sensitivity and $100 \%$ specificity in detecting human Plasmodium species. Nested PCR was carried out using genus-specific primers to confirm the presence of Plasmodium infection and if positive, speciesspecific nested PCR for all human malaria species was conducted according to Anthony et al. (2013). All genus positive samples were diagnosed to be $P$. vivax positive, except for one sample which was later found to have $P$. vivax mixed infection with $P$. malariae (unpublished data).

In this report, both patients who were diagnosed as $P$. vivax positive by nested $\mathrm{PCR}$, presented with unusual clinical outcomes after starting antimalarial treatment, even though blood smear were negative for malaria. In falciparum and knowlesi malaria, hyperparasitaemia are usually associated with poor clinical outcomes and complications (Daneshvar et al., 2009; Mangal et al., 2017). Despite that, studies have shown that the pyrogenic threshold of vivax malaria is lower than P. falciparum (Anstey et al., 2012). High parasite densities are not a typical feature of severe vivax (Quispe et al., 2014). To our knowledge, there are no sub-microscopic severe $P$. vivax cases being reported.

In Case 1, the patient presented with acute kidney injury (AKI) and experienced haemolysis few days after the ACT treatment. The delayed haemolytic anaemia was likely to be artemether treatment induced. This scenario is not uncommon as delayed haemolytic anaemia has been reported in other studies with patients receiving ACT treatment. Though the causal relationship between artemether treatment and delayed haemolytic anaemia is yet to be identified (Jarvis et al., 2013; Hasegawa et al., 2018), it is advisable that healthcare professionals should be cautious about the potential of haemolytic complications post treatment.

Acute kidney injury, formerly known as acute renal failure, is defined as serum creatinine $>3 \mathrm{mg} / \mathrm{dL}$ and reduced urine output ( $<400 \mathrm{~mL} / 24$ hours) (Kute et al., 2012). It is a serious complication of falciparum malaria and a major cause of morbidity and mortality in severe malaria. At a lesser extent, acute kidney injury had also been reported in vivax malaria (Anstey et al., 2012). The renal involvement in P. falciparum and $P$. vivax infection may be due to erythrocyte abnormalities, particularly, the formation of rosettes and clumps by sticky parasite-infected red blood cells, which causes impaired microcirculation of internal organs (Barsoum, 2000). Events such as endothelial cytoadherence, sequestration, increased whole blood viscosity and obstruction of capillary lumen can happen when parasitized erythrocytes aggregates together and hence, causing AKI. Nonetheless, several other factors contributing to the occurrence of AKI in $P$. vivax patients had been suggested such as heavy parasitaemia, hypotension, volume depletion, hyperbilirubinemia, sepsis, intravascular haemolysis and disseminated intravascular coagulation (Prakash et al., 2003).

Pulmonary complications have been described to be associated with $P$. falciparum, and rarely $P$. vivax and $P$. ovale (Martínez et al., 2005). The spectrum of malaria pulmonary complications ranges from cough, non-cardiogenic pulmonary oedema, through acute lung injury to ARDS (Tan et al., 2008; Val et al., 2017). Many studies have shown that most respiratory impairments due to malaria begin several hours after antimalarial treatments start, therefore suggesting a possible association between treatment initiation and pulmonary complications (Val et al., 2017). Even though the underlying mechanisms of this association are not entirely understood, pulmonary vascular sequestration of $P$. vivax and post-treatment inflammatory response are believed to contribute to the occurrence of these respiratory impairments (Tan et al., 2008). Nonetheless, severe respiratory symptoms may occur before antimalarial treatment is given (Sarkar et al., 2010).

\section{CONCLUSION}

As far as we know, these are the first reported submicroscopic $P$. vivax cases which developed complications after antimalarial treatments were initiated. Limited understandings of the association between low malaria parasite burden and development of complications have also become a challenge to explain the development of complications. Nevertheless, we cannot exclude that the patients may have had an unusual toxic reaction to therapy or some other syndrome leading to renal failure and pneumonia. Differential diagnosis should be considered while dealing with $P$. vivax infection. Early detection and immediate disease management with adequate supportive therapy may reduce morbidity and mortality. Vigilant monitoring and observation is important in managing malaria as the manifestation may vary from asymptomatic to severe complications and death. Hence, malaria cases particularly from a remote area and lack of easy access to medical facilities should be admitted to hospital so that complications can be monitored closely. 


\section{Conflict of interests}

The authors declare no conflict of interest.

\section{Funding}

JHT was supported by the Ministry of Education Malaysia Long Term Research Grant Scheme (LR002D-2018).

\section{REFERENCES}

Anstey, N.M., Douglas, N.M., Poespoprodjo, J.R. \& Price, R.N. (2012). Plasmodium vivax: Clinical Spectrum, Risk Factors and Pathogenesis. Advances in Parasitology 80: 151-201. https://doi.org/10.1016/B978-0-12-397900-1.00003-7

Anthony, C., Mahmud, R., Lau, Y.L., Syedomar, S.F. \& Sri La Sri Ponnampalavanar, S. (2013). Comparison of two nested PCR methods for the detection of human malaria. Tropical Biomedicine 30(3): 459-466.

Barsoum, R.S. (2000). Malarial Acute Renal Failure. Journal of the American Society of Nephrology 11(11): 2147-2154.

Daneshvar, C., Davis, T.M.E., Cox-Singh, J., Rafa'ee, M.Z., Zakaria, S.K., Divis, P.C.S. \& Singh, B. (2009). Clinical and laboratory features of human Plasmodium knowlesi infection. Clinical Infectious Diseases 49(6): 852-860.

Hasegawa, C., Kudo, M., Maruyama, H. \& Kimura, M. (2018). Severe delayed haemolytic anaemia associated with artemether-lumefantrine treatment of malaria in a Japanese traveler. Journal of Infection and Chemotherapy 24(3): 216-219. https://doi.org/10.1016/j.jiac.2017.10.008

Howes, R.E., Battle, K.E., Mendis, K.N., Smith, D.L., Cibulskis, R.E., Baird, J.K. \& Hay, S.I. (2016). Global epidemiology of Plasmodium vivax. The American Journal of Tropical Medicine and Hygiene 95: 15-34. https://doi.org/10.4269/ajtmh.160141

Jarvis, J.N., Coltart, C.E., Pule, M., Chiodini, P.L. \& Doherty, T. (2013). Artemisinin therapy and severe delayed haemolysis. The Lancet 382(9887): 180. https://doi.org/ 10.1016/S0140-6736(13)60812-0

Kute, V.B., Trivedi, H.L., Vanikar, A.V., Shah, P.R., Gumber, M.R., Patel, H.V., Goswami, J.G. \& Kanodia, K.V. (2012). Plasmodium vivax malaria-associated acute kidney injury, India, 20102011. Emerging Infectious Diseases 18(5): 842-845. https:// doi.org/10.3201/eid1805.111442

Mangal, P., Mittal, S., Kachhawa, K., Agrawal, D., Rath, B. \& Kumar, S. (2017). Analysis of the clinical profile in patients with Plasmodium falciparum malaria and its association with parasite density. Journal of Global Infectious Diseases 9(2): 60-65. https://doi.org/10.4103/0974-777X.201626

Martínez, S., Restrepo, C.S., Carrillo, J.A., Betancourt, S.L., Franquet, T., Varón, C., Ojeda, P. \& Giménez, A. (2005). Thoracic manifestations of tropical parasitic infections: A pictorial review. RadioGraphics 25(1): 135-155.

Ministry of Health Malaysia. (2014). Management guidelines of malaria in Malaysia. Available at https://books.google. com.my/books/about/MYCDCGP_Management_ Guideline_of_Malaria.html? id=E8ZcDwAAQBAJ\&redir_ esc $=y$. [Accessed 23 November 2019]

Prakash, J., Singh, A.K., Kumar, N.S. \& Saxena, R.K. (2003). Acute renal failure in Plasmodium vivax malaria. The Journal of the Association of Physicians of India 51: 265-267.
Quispe, A.M., Pozo, E., Guerrero, E., Durand, S., Baldeviano, G.C., Edgel, K.A., Graf, P.C. \& Lescano, A.G. (2014). Plasmodium vivax hospitalizations in a monoendemic malaria region: Severe vivax malaria? The American Journal of Tropical Medicine and Hygiene 91(1): 11-17. https://doi.org/10.4269/ ajtmh.12-0610

Sarkar, S., Saha, K. \& Das, C.S. (2010). Three cases of ARDS: An emerging complication of Plasmodium vivax malaria. Lung India: Official Organ of Indian Chest Society 27(3): 154-157. https://doi.org/10.4103/0970-2113.68323

Tan, L.K., Yacoub, S., Scott, S., Bhagani, S. \& Jacobs, M. (2008). Acute lung injury and other serious complications of Plasmodium vivax malaria. The Lancet. Infectious Diseases 8(7): 449-454. https://doi.org/10.1016/S1473-3099(08) 70153-1

Val, F., Machado, K., Barbosa, L., Salinas, J.L., Siqueira, A.M., Costa Alecrim, M.G., Portillo, H.D., Bassat, Q., Monteiro, W.M. \& Guimarães Lacerda, M.V. (2017). Respiratory complications of Plasmodium vivax malaria: Systematic review and meta-analysis. The American Journal of Tropical Medicine and Hygiene 97(3): 733-743. https://doi.org/10.4269/ ajtmh.17-0131

World Health Organization. (2016). Malaria terminology. Geneva: World Health Organization.

World Health Organization. (2019). Guidelines for the treatment of malaria. Third edition. Geneva: World Health Organization. 